\title{
COASTAL ENGINEERING EDUCATION AND COASTAL MODELS
}

\author{
J. William Kamphuis ${ }^{1}$
}

This paper discusses how coastal engineers are educated and how that must be changed in order to be able to meet the future demands for coastal engineers. It also addresses the use of coastal models as a vital tool to demonstrate concepts and processes that are not innately familiar to the students.

Keywords: coastal, design, education, engineering, numerical models, physical models.

\section{ON COASTAL ENGINEERING EDUCATION}

\section{Introduction}

The basic assumption of this paper is:

In light of climate change and increasing water levels, there will be an increasing and urgent need for coastal engineers who can actually design and supervise construction of coastal projects.

Some background:

Most new students are not innately familiar with even the basic wave kinematics and dynamics in coastal processes. Demonstration and hands-on experience are great tools to teach and learn these principles. Experience has shown that such demonstration and hands-on instruction can best be achieved through the use of coastal models, particularly physical models.

Prior to coming to university, students have mainly been 'coached', rather than taught, where coaching may be defined as guiding an individual through a process that uses much direct experience and practice (as in sports, music, etc.). This is another good reason for using hands-on exposure.

Using models to demonstrate principles and processes is an indispensable tool in coastal design, as will be seen in the next section. Therefore instruction through coastal models teaches the students a basic coastal engineering tool.

Finally, many of today's young people have difficulty learning through formal lectures, no matter how carefully and interestingly the material has been crafted. The generation that grew up with the internet, social networking, flashing images, sound bites and twitter is here and Coastal Engineering education must adapt to teach those students effectively.

\section{Coastal Design}

Coastal design is difficult. It combines processes that are not clearly understood, such as bottom shear stress, wave impact, energy dissipation, erosion, accretion, and transport of sediment, pollutants and nutrients, with difficult combinations of inputs, such as water levels, waves, tides, currents and wind; and the outputs from the basic design tool (models), such as coastal morphology, environmental impact, water quality, etc. are difficult to interpret (Kamphuis, 2000). Further, coastal projects must exist within environmental and societal systems. This makes design even more difficult, as discussed in Kamphuis (2005, 2006, 2008 and 2010).

The contemporary coastal design process is shown in Figure 1. Uncertainties in the data, in our understanding of coastal processes, and in our design methods are high. Therefore, design by simply combining existing knowledge with data ("desk study" in Figure 1) can only produce very approximate solutions that normally result in conservative designs. Such designs can be improved by trial and error.

Since it is not feasible to perform trial and error in the prototype, coastal design makes extensive use of models. The trial and error process is shown in Figure 1, in particular by the double arrows between the 'Modeling' and 'Design' boxes.

\footnotetext{
${ }^{1}$ Emeritus Professor of Civil Engineering, Queen's University, Kingston, ON, Canada, K7L 2R4.
} 


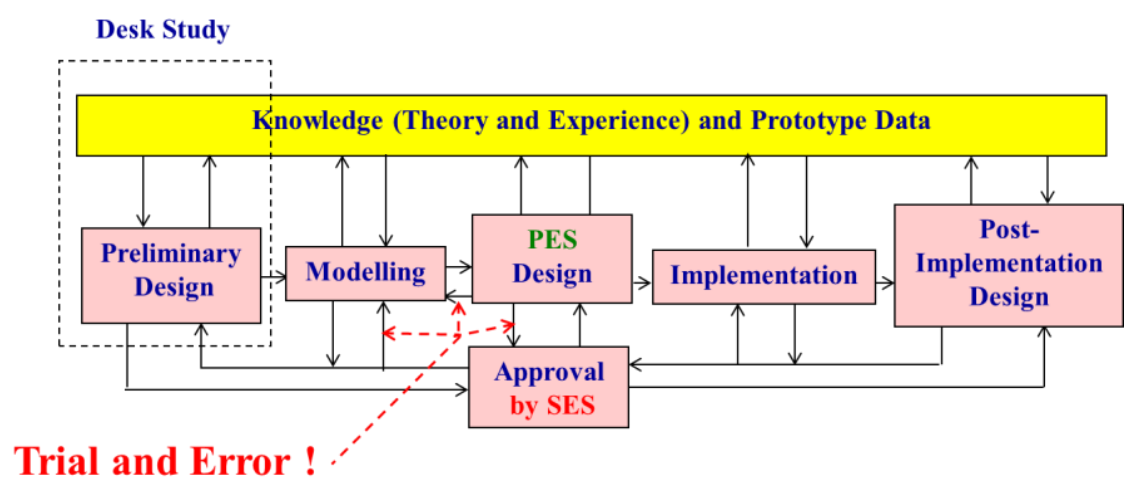

Figure 1. Contemporary Design

In addition to being the tool for design optimization through trial and error, models are also a unique tool to visualize the processes and their interactions ${ }^{2}$. Using modeling, particularly physical modeling, for visualization of coastal processes in coastal engineering courses is, therefore, directly in line with coastal engineering design methodology. Thus it teaches students how to use a very basic coastal engineering tool.

The 'Design' box in contemporary design no longer represents a simple combination of materials such as rock and sheet pile into stable coastal structures. It represents the design of Physical-Environmental Systems (PES) - (Kamphuis 2008), where PES denotes coastal projects that fit integrally within their environment. PES design accounts for the environmental interactions between projects and their environments. Further, contemporary PES design views the environment as an active partner, rather than simply as a set of regulatory rules and restrictions that must be met in design. PES design includes taking advantage of the benefits presented by the natural environment (e.g. Building with Nature, 2012).

The 'Approval' box refers to approval by the Socio-Economic System (SES), usually referred to as 'the stakeholders'. This represents approval by the various layers of governments and regulators and all the individuals and groups that could be (positively or negatively) affected by the project - Kamphuis $(2005,2006)$. Successful coastal design as in Figure 1, therefore represents a coastal design that is integrated within the environment (PES) and supported by the stakeholders (SES), as shown in Figure 2. Clearly such coastal design is complicated and requires broad knowledge and skills.

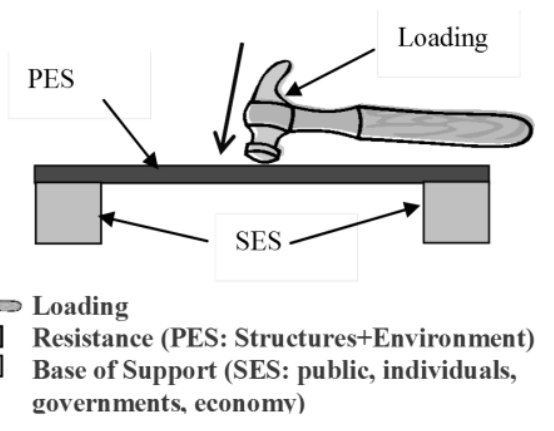

Figure 2. Coastal System

2 Models, particularly physical models, generally result in 'eureka' moments for the design team during a model study. Models are also an excellent, descriptive information tool to demonstrate the processes and results to stakeholders such as government regulators, politicians, citizen groups, etc. 


\section{Coastal Engineering Education Requirements}

This section addresses coastal engineering education that teaches students how to design as in Figures 1 and 2; coastal engineering design (synthesis) as opposed to coastal science (analysis). A student is anyone who comes to learn about coastal engineering. That could vary from young students coming directly from high school to mature engineers continuing their education.

The palette of concepts needed for successful education of such all-round coastal engineers can be divided into four categories:

Theoretical concepts: Pure and applied mathematics; sciences related to coastal engineering, such as chemistry, biology and geology;

Physical concepts, such as waves, tides, sediment transport and morphology, climate, climate variability and the interaction of physical systems with, for example, chemical, biological and environmental systems;

Design concepts: the synthesis of theoretical and physical concepts with building materials (such as stone, steel and concrete) and with materials and structures provided by nature (such as the soil foundation, sandy beaches, mangroves, reefs, wetlands), under the overall design requirement of Figure 2 - a PES supported by an SES.

Management concepts, such as communication and leadership, project management, business/ accounting and the management of coastal systems.

The above palette of necessary concepts results in a long list of needed skills and basic knowledge - ASCE (2004, 2007, 2007a), Galloway (2007), Kamphuis (2010a). Clearly there is not enough time to cover all the subjects in detail during the formal education of an engineer. The optimum pedagogical approach is to introduce coastal engineering students to all the basic materials in the skills and knowledge palette by the time they graduate, to form a strong platform from which to make exciting choices for a subsequent coastal engineering career.

\section{On Improving Coastal Engineering Education}

Undergraduate coastal engineering education should be broad and introductory, exposing the students to as many aspects of the required set of basic knowledge and skills as possible. Its graduates should be capable of participating in design of coastal systems (Figures 1 and 2). The course should be inspiring, motivating and design-oriented. It should include a focused and supervised design project or a supervised work term in a design setting.

Postgraduate coastal engineering education consists of deepening the broad undergraduate introduction. This is where changes must occur if expected demands for engineers are to be met. The following paragraphs are stated black and white to identify clearly where improvement must be made. Fortunately, there are many institutions where coastal engineering education is different than described here.

At the present time, a Master's study usually consists of some coursework plus a major project (thesis). PhD study consists of thesis work and often does not include coursework. This is a simple, immediate improvement that can be made. Surely PhD students can still benefit from coursework, in particular from coursework focused on design.

Since professors, students, projects, laboratories and equipment are all supported by research funding, the major postgraduate project (thesis) often becomes a research thesis. Clearly, good research is necessary to continue to move forward. Clearly, not all research needs to be directly applicable in design and a sizeable portion of research, also in coastal engineering needs to be 'basic'. However, 'research' is only one aspect of coastal engineering and it should not become the over-riding focus of the education of coastal engineers at the Masters and $\mathrm{PhD}$ levels.

Research-oriented Master's projects tend to produce apprentice PhDs. Research oriented $\mathrm{PhD}$ projects tend to produce apprentice professors who are subsequently held in Post-Doc holding tanks to do more research. These PhD's and Post-Docs eventually become professors or theoretically oriented experts, who know mostly research and know little about practical engineering. Professors, in turn, produce new research-oriented Masters, PhDs and Post-Docs - how can they do otherwise since they were educated in that way and their research publications generate their salaries, reputations and promotions. And on it goes.... 
To change this research-based merry-go-round and produce (many) engineers comfortable with design, we must develop a different Masters education. Masters education should not be simply an apprentice PhD education; it should be distinct and separate. Masters study must include practical work in engineering. Coursework and projects must be essentially design or project-oriented. Masters study does need to form a broad practical base for further PhD study, but it must primarily be a practical preparation for a coastal engineering career in industry. The need for such masters is great; therefore, contrary to present practice, a balanced coastal program should include many more Masters than PhDs.

To produce senior engineers comfortable with design, $\mathrm{PhD}$ thesis projects must also not be only research. They should have at least a major design component. This could be an innovative theoretical/numerical solution of a practical problem, an innovative physical/numerical model study of a design, the development for a new type of project management tool, etc. Such innovative projects should, however, still be publishable ${ }^{3}$.

This is not new. This is not unique insight. In fact... Plus ça change, plus c'est la même chose. What is proposed here is an updated version of what coastal engineering graduate education looked like 40 years ago - before the process was hijacked by the scienceoriented research merry-go-round.

Unless we find the fortitude to change post graduate coastal engineering education; unless we find funding that is not only tied to 'research'; unless professors and universities dare to be more interested in being and training practical, professional engineers, rather than chasing a research-oriented pot of gold, our existing systems will not be able to meet future needs for competent coastal engineers. In fact, in many areas, the existing educational system already fails to meet present needs ${ }^{4}$.

\section{ON COASTAL MODELS AS TEACHING TOOLS}

\section{Present Educational Formats}

We will discuss three formats of education - the Lecture/Tutorial, Problem Based Learning and Cognitive Apprenticeship.

The Lecture/Tutorial (LT) format is the most common. Often called the 'traditional' method, there is nothing sacred about it. Its main advantage is the relatively low cost. In LT, the lecturer presents concepts, theories and methods (including problem solving) in the lectures and the tutorial consists of application of those concepts under guidance of tutors (preferably including the professor). Without the tutorials this method is much less effective. Note that the tutorials are similar to coaching, discussed earlier.

Problem Based Learning (PBL) is an effort to improve on LT by focusing more on problem-solving skills (e.g. Benjamin and Keenan, 2006; Hmelo-Silver and Barrows, 2006). Students are asked to solve practical ${ }^{5}$ coastal problems and are expected to obtain the background information and the reasoning and methodology to solve that particular problem on their own, but normally with some coaching. This type of study is best done in small (3 or 4 people) project groups who work together as a team under a leader, selected from the group by its members. Normally the team under its leader's guidance presents a written and oral report at the end of the each problem study. The students learn problem-solving skills, team work and team leadership in the process, but since they will obviously focus their study on the problem at hand their knowledge will be rather focused - not the broad knowledge advocated earlier. The narrow focus of PBL can easily be broadened by requiring, interim group reports to be presented at plenary (class) discussions. That way, the students in a project group will learn from the questions and critiques by the other class members. It also exposes the

${ }^{3}$ This means basic changes are needed to the industry publishing engineering publications. Coastal Engineering publications must become more receptive to innovative engineering and design-oriented papers. That means a cultural change in the 'peer review process' is needed.

${ }^{4}$ Some readers will at this point conclude that this paper reduces engineering education to practical, college-level instruction. Think again. The list of needed concepts, skills and knowledge is much beyond college level education. Even the much broader and more intellectually oriented university educational system struggles to teach all the required material effectively. What is advocated here is simply a broad intellectually challenging university-level education with greater focus on design-oriented material and less dependence on research funding.

${ }^{5}$ Practical problems are not neatly packaged and trimmed, like assignments and textbook problems. They are normally complex and ill-defined. 
students in one project group to more than their own problem(s) through listening to and critiquing the other presentations. Students like PBL - it gives them the experience of discovery (or the feeling of 'being engineers'). PBL works very well in combination with $\mathrm{LT}^{6}$.

Cognitive Apprenticeship (CA) is an example of trying to improve on LT and PBL, (e.g. Collins et al,1991; Lindsay et al., 2008, Poitras and Poitras, 2011). The idea is that students work directly with a master (tutor) on a practical problem and learn problem solving reasoning and strategies, which are not taught in traditional LT and PBL, from the master.

$\mathrm{CA}$ is also rather focused study (not broad and general, as discussed in the previous section), but it is effective in teaching the solution of ill-defined practical problems that are prevalent in contemporary design (Figures 1 and 2).

Essentially the above methods, when well prepared and presented, are all similar with somewhat different emphasis. They all include teaching plus coaching. And all three of these educational formats will benefit greatly from extensive demonstration, and hands-on laboratory experimentation and simulation.

\section{Demonstration, Experimentation and Simulation}

In this paper, demonstration and experimentation refer more to visualization of hypothetical and theoretical concepts, while simulation refers to the modeling of actual, complex physical interactions, conditions and designs.

Coastal concepts, both simple (such as waves, wave grouping and orbital motion) and complex (such as stability of beaches and breakwaters) can be most readily demonstrated and visually understood through simple experimentation in a physical model. Physical laboratory experimentation is excellent because it is relatively easy to set up, it is immediately visual, and the tests are repeatable and can be controlled.

Such physical experiments pique students' interest; they are exciting and inspirational. There are few student experiences that can match the excitement of discovering that your physical model tests show that the breakwater section you have designed withstands the design conditions. The same exciting experiment can be enhanced by subsequently increasing the wave conditions and learning how a breakwater behaves under severe stress, how it fails and how the design can be improved.

Coastal projects generally have quite a large geographical extent and their development and interactions with their surrounding environment take a long time. Field measurements of the parameters and response of such a large coastal system over an extended time would be unaffordable. In the field, the project also cannot be subjected to arbitrary boundary conditions; the boundary conditions are imposed by nature.

For those and many other reasons, it is necessary for coastal engineers to simulate project behavior, project designs, design changes, project performance under changed boundary conditions, etc. in models. The models bring about a better overall and detailed understanding about the projects and their interactions with the environment.

Although physical models are the most informative simulation tools, they do not give good results for larger geographical areas and longer time durations (Kamphuis, 2000, 2010). Physical modeling facilities are costly. The models require much space and the model tests are time-consuming to perform. Therefore, the simulation tool of choice for larger area, longer duration tests is often the numerical model, which normally fits on an office desk and performs multi-year simulation runs in minutes to hours. Thus there are two types of simulation tools and they are used for different purposes.

\footnotetext{
${ }^{6}$ In my undergraduate coastal engineering classes, the students were asked to solve a problem on the first day of class. The problem was comprehensive, but poorly defined (e.g. fix this beach erosion problem, solve this breakwater collapse). No guidance was given, except for lecture notes, a textbook and access to a tutor to answer questions. The problem is not atypical of problems arriving at an engineering office. The class was divided into groups of four and each group was asked to nominate its own leader. The 'solution' was due in one week, in written form as well as a presentation to the class. The problem quickly put the fire under most students and it certainly inspired their innovative side. It also awakened in many an intense interest in knowing more about the subject. After 13 weeks of Lecture/Tutorial, the final problem in the course was essentially the same as the problem in Week 1. Now the solutions were based on the information gained during the course; everyone received immediate reinforcement and a good idea of how far they had progressed during the course, even before the examinations. This method inspired many students to learn more through graduate work.
} 
Learning through trial and error with models meshes exactly with coastal design protocol in Figure 1. Therefore, models as a teaching tool provide a unique opportunity to teach the students about modeling technology and scaling. In short, using models in class familiarizes students with a very basic step in design.

Finally, students who have been 'coached' through most of their education will welcome the extensive hands-on work, particularly the experimentation in a laboratory to help them understand the basic principles as well as complex, totally unfamiliar concepts. Lectures and textbooks can provide the appropriate information, but hands-on experimentation generates a more intimate familiarity with, and greater interest in the concepts.

\section{How to ensure laboratory space and time}

Most available funding is for 'research'. Funding is seldom earmarked for education or for maintenance of facilities and equipment. This problem was discussed earlier in a related, but slightly different context by Kamphuis (2011).

As a result, course organizers need to be innovative. They should carefully search out all the options to ensure laboratory space and time for teaching.

Grants are always the first option that comes to mind. But grants are usually research oriented. Even infrastructure grants are for new facilities and do not support existing facilities and maintenance. Therefore grant applications offer little opportunity to develop or maintain a teaching facility.

It is, however, entirely possible to fit the teaching of coastal concepts into a laboratory schedule that is essentially dedicated to research. Since not all equipment is used full-time for research projects, there is always room for instructional time. It is very probable that the research-oriented laboratory can exist only by virtue of university or departmental infrastructure support. That alone is sufficient argument to force sharing the laboratory space and time for instruction. Conversely, the use of the facilities for instruction in a number of courses can be used to justify the provision of infrastructure funding for such a research laboratory to the university management ${ }^{7}$. The key issue is to arrive at some binding agreement for annual time and space; otherwise it is easy for 'important' research to claim priority over 'less important' teaching.

Private donations are another fundraising method that should be explored. Since solicitation of donations is normally a jealously guarded privilege of a central university gifting office, strong proposals about training coastal engineers must be made through such central facilities.

Co-operation with a commercial modeling facility is another option, and it offers great perspective. The students are excited about being able to do the laboratory work off-campus. The laboratory gets an inside track on prospective temporary and permanent employees. It creates opportunity for information exchange through cross appointments of laboratory staff as adjunct faculty and of professors as advisors to the laboratory. It also facilitates collaboration on instruction. The laboratory may be in a position to apply for additional government support, once it has formulated a clear objective to contribute to engineering education. Of course, the most successful co-operative ventures are those between institutions that are geographically close ${ }^{8}$. If the co-operation involves longer distances, this kind of co-operation becomes more difficult, but certainly not impossible 9 .

Building your own laboratory with your own resources is another opportunity. This will be a mix of project design, PBL, extensive student involvement from various faculties and departments, technician help and construction methodology. This alternative is inexpensive, but time-consuming; it needs ingenious planning and commitment of time and effort for several years. But it is a distinct alternative, particularly since its design and construction can be used as projects in multi-disciplinary design and construction courses.

Finally, coastal engineering education must take note of a promising new trend: Many universities now recognize that 'educational experience' (such as the availability of hands-on

7 Queen's University has over 40 years of experience with this model

8 Examples are the co-operation between the Technical University Delft and Deltares, both in Delft, and between University of Ottawa and the Coastal Hydraulics Centre in Ottawa.

9 Queen's University in Kingston has co-operated with the Canadian Hydraulics Centre in Ottawa from time to time for over 40 years. The distance between them is $170 \mathrm{~km}$. 
experience in coastal engineering) makes happy students and attracts excellent prospective students. Coastal Engineering education needs to lead and exploit this trend.

\section{Conclusions}

Shakespeare's gives Hamlet the words: 'To be or not to be..., that is the question'. He could have written these words for coastal engineering in 2012. Paraphrasing: 'To be (coastal engineers who can design) or not to be... that is the question'.

This paper shows that to be coastal engineers, design must be a vital part of the curriculum. The paper also shows that demonstration through simulation and modeling is highly desirable and that obtaining laboratory space and time for coastal engineering instruction is difficult, but not impossible.

The conclusions of this paper are:

To develop engineering graduates who are capable of design and of management of coastal engineering design and construction projects, we must find the courage and the ways to remodel our research-oriented postgraduate education into a more design-oriented education.

Access to simulation and physical laboratory facilities for teaching must be a priority in coastal engineering education for the following reasons: Physical laboratory experimentation and simulation through physical and numerical models demonstrate difficult coastal concepts and develop intimate familiarity with them. Experimentation also introduces an element of coaching, which is much needed with today's students. Finally, hands-on instruction and experimentation generates a keen interest in the students.

\section{References}

ASCE 2004. Civil engineering body of knowledge for the 21st Century, American Society of Civil Engineers Publications, Reston, VA, USA.

ASCE 2007. The vision for civil engineering in 2025, American Society of Civil Engineers Publications, Reston, VA, USA.

ASCE 2007a. Preparing the civil engineer for tomorrow by raising the bar, Civil Engineering, Sep 2007, 64-71, American Society of Civil Engineers Publications, Reston, VA, USA.

Benjamin, C. and Keenan, C. 2006. Implications of introducing problem-based learning in a traditionally taught course. Engineering Journal of Higher Education. Academy of Engineering Subj. Centre, 1 (1), 2-7.

Building with Nature 2012. www.ecoshape.nl

Collins, A., Brown, J. S. and Holum, A. 1991. Cognitive apprenticeship: Making thinking visible, American Educator, 15 (3), 6-11, 38-46.

Galloway, P.D. 2007. The 21st century engineer- a proposal for engineering education reform, American Society of Civil Engineers Publications, Reston, VA, USA.

Hmelo-Silver, C. E. and Barrows, H. S. 2006. Goals and strategies of a problem-based learning facilitator , Interdisciplinary J. of Problem-based Learning, 1 (1), 21-39.

Kamphuis, J.W. 2000. Designing with Models, Proceedings of 27th International Conference on Coastal Engineering, ASCE 19-32.

Kamphuis, J.W. 2008a. Coastal system resilience, Proceedings of 31st International Conference on Coastal Engineering ASCE 4302-4315.

Kamphuis, J.W. 2010. Introduction to Coastal Engineering and Management, 2nd Ed. World Scientific Press, Singapore, 522 pp.

Kamphuis, J.W. 2010a. Perspective on coastal engineering practice and education, Handbook of Coastal and Ocean Engineering", Ch 42, World Scientific Press, Singapore, 1135 - 1163.

Kamphuis, J.W. 2011. Coastal Engineering - Theory and Practice, Proceedings of Coastal Sediments 2011, World Scientific Press, Singapore, 1-14.

Lindsay, E., Munt, R., Rogers, H., Scott, D. and Sullivan, K. 2008. Making students engineers. Eng. Education J. of the Higher Ed. Academy of Engineering. Subj. Centre, 3 (2), 28-36.

Poitras, G. and E. Poitras 2011. A cognitive apprenticeship approach to engineering education, the role of learning styles", Journal of Engineering Education (6), Issue 1, 63-72. 